\title{
Bibliographic Utilities and Latin American Collections
}

\section{Ketty Rodríguez}

\begin{abstract}
There appears to be a conflict between the principles of cooperation in cataloging and the acquisition of Latin American materials. A recent look at the literature revealed that the availability of copy cataloging for Latin American imprints in the bibliographic utilities seems to be on the decline. The author surveyed large, medium, and small Latin American collections via the Internet to determine the usefulness of bibliographic utilities for cataloging Latin American material. It was found that some large collections use more than one utility. Library representatives said their institutions were using more than one utility because they were trying to receive the maximum benefit from copy cataloging. Some catalogers of Latin American imprints seem unaware of the decline of copy cataloging in the bibliographic utilities that has been documented in the literature.
\end{abstract}

Cooperation among libraries is one of the most discussed topics in library literature. The drive toward standardization, which paved the way for automation, has been done with the ultimate purpose of enhancing cooperation.

Over time, library cooperation has taken several forms: cooperative acquisitions and collection development, and cooperative cataloging. One of the most successful cooperative efforts in the area of acquisition/collection development was the Farmington Plan (Hendrik 1973), which divided responsibilities for acquisitions among the large research libraries in the United States. The ultimate purpose was to build basic research collections across the country to fulfill research and curriculum needs of faculty and students and at the same time to develop a unique research collection that was based on assigned subject or country responsibility. Because the responsibilities were assigned for a predetermined subject or for a particular country collection, the chances of overlap were greatly reduced. Even after the Farmington Plan was no longer operational, libraries continued to honor their commitments and research collections continued adding library materials in their assigned areas (Grover 1991).

Cooperative cataloging of library material was stimulated by the development of bibliographic networks in the 1970s. The emergence of the OCLC Online Computer Library Center, Inc. (OCLC), the Research Libraries Information Network (RLIN), and the Western Library Network have had a great impact on the library community. From the beginning these bibliographic utilities allowed many libraries to automate their processes and, at the same time, achieve economies of scale.

KetTy Rodríguez is Assistant Professor, School of Library Science and Information Studies, Texas Woman's University (f_rodriguez@venus.twu.edu). Manuscript received October 13, 1995; revised April 28, 1996; accepted for publication July 2, 1996. 
More recently, however, some authors (Avram 1979; Sercan 1994) have questioned the benefits derived from these bibliographic utilities. One author has suggested that because there are different reasons for cooperation in acquisitions, collection development, and cataloging, institutional conflict can arise among them (Grover 1991, 407). For example, the goal of cooperative collection development is that at least one copy of any item of research value must be made available somewhere in the United States. Implicit in this goal is the value of diversity or the uniqueness of library collections. But shared cataloging is based on the principle of taking advantage of the homogeneity, similarity, or overlap in library collections. One of the primary reasons for belonging to a bibliographic utility is to decrease the cost of original cataloging.

In the literature on cataloging Latin American materials, a sentiment has been expressed that the uniqueness of Latin American collections means that they benefit less from bibliographic utilities than other, more standard collections. In fact, a librarian at Cornell University stated that when they started processing material locally in 1988, they stopped including their records in the RLIN database. She wrote: "Now other RLIN libraries are following this route and not entering their acquisition data on the utility" (Sercan 1994, 59). Several authors have written about the loss of autonomy suffered by library management when they subscribe to a bibliographic utility (Martin 1986; Hafter 1986). Often, cataloging departments follow the directions established by the bibliographic utility rather than the individual needs of their own institutions (Hafter 1986). The result is an unwanted loss of autonomy by the library cataloging department, with a subsequent loss in the staff's feeling of professional worth.

The 1970 s were characterized by the growth of bibliographic utilities. During that time technology was still very expensive and not nearly as powerful as today. Therefore, bibliographic utilities were indispensable for many libraries interested in automating various processes. But in the 1980s, more powerful and less costly technologies became available, such as CD-ROMs. There has been a spate of local networks made up of carefully selected sister institutions whose online catalogs are accessible to each other. With the growth of the Internet, many libraries are finding that catalogs of other institutions are readily available.

The impact of these developments has not been overlooked by OCLC and RLIN. In a seminar sponsored by OCLC in January 1991, concern was expressed that: "if no data exchange occurs then the resulting isolation of libraries jeopardizes national resources, and consequently effective library services" (Lowell 1991, 100).

The realization by many libraries that there might be various new ways to perform tasks once carried out by bibliographic utilities, plus the drive toward greater homogeneity (Perrault 1994) in academic libraries, tends to bring into question the usefulness of bibliographic utilities for copy cataloging of Latin American imprints. The central questions posed are: (1) Which bibliographic utilities are currently being used by Latin American collections? (2) Is there a pattern of use of these bibliographic utilities? (3) What is the usefulness of the utility in terms of the amount of copy cataloging for Latin American imprints? and (4) What are the possible causes of the decline in the usefulness of bibliographic utilities for the copy cataloging of Latin American materials?

\section{LATIN AMERICAN COLLECTIONS AND THE INTORMATION EXPLOSION}

In an environment with an explosion of publications with ever-increasing prices, librarians are struggling to maintain their collections while being confronted with budget cuts, staff reductions, and technological changes. With tax revolts reducing government revenues, and an aging population requiring more of the public resources that remain, universitiesperceived as another self-serving bureaucracy-are receiving far less support than in the past. Area study collections that once were the library vanguard are 
now seen as relics of an outdated library philosophy that emphasized ownership over access (Hazen 1993, 269). Despite the support received by area studies during the post-war period, area studies were struggling for survival by the 1980s. Area studies flourished in the post-war period, "only to collapse with the advent of peace" (Merkx 1993, 294). Some universities, to save staff and cut costs, have merged the special collections into the general collection. Others have eliminated special language and area catalogers, expecting the cataloging to be obtained through the bibliographic utility (Grover 1991, 407).

In a 1983 study, Grover (1991) searched RLIN and OCLC databases to determine the speed of copy cataloging for 298 Spanish-language Latin American imprints. The researcher found that slightly more than one-third was cataloged during the first six months and only one-twelfth during the last six months. The author found that a year after receiving 298 Spanish-language imprints, 50\% of the books had not been cataloged anywhere in the United States. The author also found that there was little difference between the two utilities because both had the same number of books, although not the same books. Sercan (1994) carried out a similar study in 1992 with 783 Latin American Spanish-language imprints. Both studies used similar methodologies, and the purpose was the same: to gauge the speed of copy cataloging. In the more recent study, Sercan spaced the inquiry every four weeks instead of every six months. In this second study, the author found a marked decline in copy cataloging. In each study, the authors found that allowing more time slightly improved the results.

At a time when institutions of higher education should be finding ways to prepare Americans for globalization, proficiency in foreign languages, and cross-cultural skills, the resources to support these goals, have declined. In recent research, Perrault $(1994,187)$ has revealed that institutions of higher education are buying fewer foreign-language materials. The author compares the nonserials acquired by 72 ARL libraries in 1985 with those acquired in 1989. The researcher found an overall decline in the total number of nonserial imprints acquired by these libraries. She also noted an alarming decline in foreign-language acquisitions, a decrease in unique titles on subject areas and an increase in the acquisition of core material. The net result of these trends will likely produce more homogeneity and less diversity in library collections. Such results would have serious implications for research and resource sharing.

This shift of attention away from foreign materials and from area studies is further documented in a study (Leazer and Rohdy 1994) on the level and quality of bibliographic control of foreign monographs. In this study, the authors aimed to answer the following questions: To what extent is effective bibliographic control maintained over foreign publications? What proportion of the material is aequired and cataloged? Is the quality of cataloging sufficient? What are the specific quality problems encountered? and Is the material controlled in a timely manner?

After analyzing in depth more than fourteen studies, they conducted a baseline study. The results of their study confirmed (p. 41) "that the differences in treatment of foreign and domestic monographs is real and might even be greater than suggested by previous research. Of special concern is the lack of any control over a significant proportion of foreign research monographs." The quality of the records for foreign monographs was lower than the quality for domestic monographs, but the differences in quality were not as large as the differences in the extent of the coverage.

\section{Methodology and Data ANalysis}

A survey of Latin American collections, selected by size, was conducted by using the Latin Americanists Librarians Annoucements List (LALA_L) on the Internet. LALA_L is a moderated list prepared by Gayle Williams of the Cataloging Department at the University of Georgia Libraries in Athens, Georgia.

For the sake of consistency and comparison, the Latin American collections 
TABLE 1

Groups of Collections SuRVEyed by DEAL

\begin{tabular}{lll}
\hline Group I-190,000 or more & Group II-100,000 to 189,000 & Group III-100,000 or less \\
\hline Cornell & Arizona & Brigham Young \\
Duke & Arizona State & London \\
Florida & California San Diego & New York University \\
Illinois & Massachusetts & Notre Dame \\
New Mexico & Miami & Ohio State \\
North Carolina & Minnesota & Pennsylvania State \\
Pittsburgh & San Diego State & Rutgers \\
Princeton & Vanderbilt & \\
Puerto Rico & & \\
Southern California & & \\
Texas & & \\
California & \\
UCLA & & \\
Yale & \\
Wisconsin & \\
Stanford & & \\
\hline
\end{tabular}

included in this study are roughly the same collections used by Deal (1993). A questionnaire consisting of 5 questions was posted on LALA_L on February 22, 1996; a total of 15 responses were received. This represents $50 \%$ of the 30 responses received by Deal (1993), which were classified by size into 3 groups.

Group 1 included those libraries with 190,000 volumes or more; Group 2, libraries with 100,000 to 189,000 volumes; and Group 3, libraries with fewer than 100,000 volumes. Nine of the libraries $(60 \%)$ in Group 1 responded; 4 (50\%) from Group 2 responded; and 2 (28\%) from Group 3 replied.

The questions were:

1. What bibliographic utility is currently being used to catalog Latin American material? Specify the starting date of the use of the utility.

2. If you have switched to a different bibliographic utility, indicate both utilities, the date of the switch, and the reason for the change.

3. If you are using more than one utility indicate the reason why.
4. Rank the usefulness of each utility. (Use 1 to indicate the most useful and 4 for the least useful.)

5. Indicate the possible causes for the decline in the usefulness of bibliographic utilities for copy cataloging of Latin American imprints. (Use 1 as the most imporant cause and 4 as the least important cause.)

_ Decrease of the hit rate.

_ Decrease of quality

- Too expensive

_ Loss of autonomy of administrators Alternative resources Other

The usage of bibliographic utilities by Latin American collections is shown by library size in tables 2-6. Of the 15 respondents, 14 (93\%) use OCLC. Only one uses RLIN exclusively. Three libraries currently use both utilities. The larger collections have switched utilities but the other two groups continue to use the original utility selected. One reason for switching, or in having both utilities, is that the librarian was looking for a higher hit rate, and thus faster processing of Latin Ameri- 
TABLE 2

USAGE OF BIBLIOGRAPHIC UTILITIES BY LARGE COLLECTIONS

\begin{tabular}{lcl}
\hline \hline Group I & $\begin{array}{c}\text { Bibliographic } \\
\text { Utility }\end{array}$ & \multicolumn{1}{c}{$\begin{array}{c}\text { Dates } \\
\text { of Usage }\end{array}$} \\
\hline Cornell & OCLC & $1973-1981$ \\
& RLIN & $1981-1988$ \\
Duke & OCLC & $1980-$ \\
Florida & OCLC & $1975-$ \\
N. Carolina & OCLC & $1978-$ \\
Puerto Rico & OCLC & $1988-$ \\
S. California & OCLC & $1976-1985$ \\
& RLIN & $1985-$ \\
Texas & OCLC & $1974-$ \\
UCLA & OCLC & $1978-$ \\
Yale & OCLC & $1974[?]-1977$ \\
& RLIN & $1977-$ \\
& OCLC & $1994-$ \\
\hline
\end{tabular}

can imprints. The reasons given by librarians at two libraries using both utilities were "We are trying to get as much copy cataloging as is available" and "We use both because the bibliographic record appears faster in OCLC than RLIN but sometimes we can not find the item in OCLC and we can in RLIN."

Respondents from the largest collections also offered details about their relationships with the utilities. Librarians from Cornell said that since 1988 they have done their cataloging on their local system and that tapes of this work are sent weekly to RLIN. They also noted that they are currently considering the use of FTP (file transfer protocol) for data exchange. Librarians from the University of Southern California commented that although they are using OCLC primarily, they upload records to RLIN on a monthly basis. The librarians at Yale University, who observed that Yale is a founding member of RLG/RLIN, use their local system like Cornell, and upload their records to both OCLC and RLIN. Librarians from the University of North Carolina indicated that $85 \%$ of their Latin American collection has been cataloged.
TABLE 3

USAGE OF BIBLIOGRAPHIC UTILITIES BY MEdium Size COLLECTIONS

\begin{tabular}{lcc}
\hline Group II & $\begin{array}{c}\text { Bibliographic } \\
\text { Utility }\end{array}$ & $\begin{array}{c}\text { Dates } \\
\text { of Usage }\end{array}$ \\
\hline Miami & OCLC & $1978-$ \\
Minnesota & OCLC & \\
San Diego State & OCLC & $1977-$ \\
$\begin{array}{l}\text { California, } \\
\text { San Diego }\end{array}$ & OCLC & \\
\hline
\end{tabular}

TABLE 4

USAGE OF BIBLIOGRAPHIC UTILITIES BY SMALL COLLECTIONS

\begin{tabular}{lcc}
\hline \hline Group III & $\begin{array}{c}\text { Bibliographic } \\
\text { Utility }\end{array}$ & $\begin{array}{c}\text { Dates } \\
\text { of Usage }\end{array}$ \\
\hline Brigham Young & RLIN & $1978-$ \\
London & OCLC & $1977-$ \\
\hline
\end{tabular}

TABLE 5

RANKING OF USEFULNESS OF BIBLIOGRAPHIC UTILITIES

\begin{tabular}{lcc}
\hline \hline Utility & Rank & Libraries \\
\hline OCLC & 1 & 14 \\
OCLC \& RLIN & $2^{\circ}$ & 1 \\
RLIN & 4 & 1 \\
\hline
\end{tabular}

"Two libraries used two utilities. One ranked them both as 2 . The other one ranked RLIN as 4 .

TABLE 6

Possible Causes of Decline in USEFULNESS OF UTILITIES

\begin{tabular}{lcc}
\hline Possible Causes & Rank & Libraries \\
\hline Decrease of hit rate & 1 & 5 \\
Decrease of quality & 2 & 3 \\
Too expensive & & 0 \\
Loss of autonomy & & 0 \\
Alternative resources & & 0 \\
Other & & 7 \\
\hline
\end{tabular}


In the "other" category, 6 of the 7 librarians questioned the premise that the usefulness of the utilities has declined. If there has been a decline, they argued, it is probably connected to cut-backs that have limited the number of catalogers hired to do original cataloging. One librarian provided numbers of books cataloged at her institution in 1995 and 1996. For 1995 the cataloging team for Iberia-including Spanish, Catalan, Portuguese, and Gallegan material-and Latin America copy cataloged 6,242 books with copy and 1,390 without copy cataloging. So far in 1996 the same team has cataloged 4,729 books with copy and 905 without copythis includes about 1,500 new books sent to the backlog. The librarian giving the statistics demurred any comment on the decline because she could not give an accurate number due to the substantial backlog.

\section{Conclusions}

OCLC was utilized by 14 of the 15 Latin American collections. Most of the libraries began to use the utility in the 1970s. Three of the largest collections used both OCLC and RLIN. The librarian for one of those three collections ranked both utilities in the highest category. However, another ranked both utilities in the second category, while the third considered OCLC very useful but ranked RLIN as the least useful.

Two reasons were given by the librarians for the use of both utilities: (1) they wanted to take advantage of as much copy cataloging as possible and (2) OCLC is often faster than RLIN, but they have more success finding the copy cataloging in OCLC than in RLIN.

The data indicate that the growing backlog may be caused by the fact that fewer catalogers are doing original cataloging. At the same time, one can also see from the data that the utilities are being used less and less frequently for copy cataloging, thus exacerbating the growing backlog. If the utility is less useful in providing copy cataloging, then the backlog continues to grow. However, 10 of the 15 $(66 \%)$ respondents did not agree with the literature cited about the reasons for the decline in copy cataloging. Those who protested claim that they depend heavily on the utilities for copy cataloging and yet the backlog continues to grow.

Five of the respondents (33\%) maintain that if there is a decline in quality (which they doubt) it may be due to a decline in the number of hits. Only three respondents $(20 \%)$ felt that there was a decline in quality. The remainder of those answering mentioned that they do not agree that there is a decline as claimed in the literature.

The comments by the librarians were telling. One asked me to refer her to the studies alleging a decline in the availability of copy cataloging for Latin American imprints. Another librarian agreed that there was an overall decline in buying power, but alleged that her budget had increased due to funding from private sources.

It would appear that due to a growing backlog, perhaps brought about by reduction of staff doing original cataloging, librarians in charge of Latin American collections have been slow to recognize the reduction in the availability of copy cataloging records in the bibliographic utilities. This decline has been documented in the literature concerning Spanish-language material destined for Latin American collections. Many of the librarians in charge of Latin American collections depend heavily on copy cataloging available from the bibliographic utilities. The decline may be due to the use of the utility and the procedure used by the system. If this is the real explanation, then it would also explain the growing numbers of backlogs.

\section{WORKS CITED}

Avram, Henriette. 1979. Effect of national networking decisions. In Requiem for card catalog management: Issues in automated cataloging, ed. Daniel Gore, Joseph Kimbrough, and Peter Spyers-Duran. Westport, Conn.: Greenwood.

Deal, Carl. 1993. A survey of Latin American collections. In Latin American studies into the twenty-first century: New focus, new formats, new challenges. Papers of the Thirty-Sixth Annual Meeting of the Seminar on the Acquisition of Latin American 
Library Materials. University of California, San Diego and San Diego State University. 1-6 June 1991. New Mexico: SALALM Secretariat University of New Mexico, 315-24.

Grover, Mark L. 1991. Cooperative cataloging of Latin American books: The unfulfilled promise. Library resources of technical services 35 : 406-15.

Hafter, Ruth. 1986. Academic libraries and cataloging networks: Visibility quality control and professional status. Westport, Conn: Greenwood.

Hazen, Dan C. 1993. Latin American studies, information resources, and library collections: The contexts of the crisis. In Latin American studies into the twenty-first century: New focus, new formats, new challenges. Papers of the Thirty-Sixth Annual Meeting of the Seminar on the Acquisition of Latin American Library Materials. New Mexico: SALALM Secretariat University of New Mexico, 269.

Hendrik, Edelman. 1973. The death of the Farmington Plan. Library journal 98: 1251-63.

Leazer, Gregory H., and Margaret Rohdy. 1994. The bibliographic control of foreign monographs: A review and baseline study. Library resources \& technical services 39 : 29-42.
Lowell, Gerald R. 1991. Special section: report from the OCLC/RLG seminar. Cited in Local systems and bibliographic utilities: Data exchange options: Keynote address. Information technology and libraries 10: 102.

Martin, Susan K. 1986. Library networks, 1986-1987: Libraries in partnership. New York: Knowledge Industry.

Merkx, Gilbert W. 1993. The progress of alliance: Confronting the crisis in resources for foreign area studies in the United States" In Latin American studies into the twenty-first century: New focus, new formats, new challenges. Papers of the ThirtySixth Annual Meeting of the Seminar on the Acquisition of Latin American Library Materials. New Mexico: SALALM Secretariat University of New Mexico, 294.

Perrault, Anna H. 1994. The changing print resources base of academic libraries in the United States: A comparison of collective patterns in seventy-two ARL academic libraries of non-serial imprints for the years 1985-1989. Ph.D. thesis. Florida State University, School of Library and Information Studies.

Sercan, Cecilia. 1994. "Where has all the copy gone? Latin American imprints in the RLIN database." Library resources of technical services 38: 561-69. 